\title{
Sexo e cosmopolitismo na prosa de ficção da Belle Époque brasileira: Mademoiselle Cinema e Madame Pommery*
}

\author{
Estela Carielli de Castro ${ }^{* *}$ \\ Universidade Federal de Pernambuco \\ Recife, Brasil \\ Recebido em: 29/04/2019 \\ Aceito em: 30/07/2019
}

\begin{abstract}
Resumo: Este artigo visa analisar Madame Pommery, de Hilário Tácito, e Mademoiselle Cinema, de Benjamim Costallat, com foco nas personagens principais e como elas são retratadas, levando em consideração que estão inseridas no contexto da Belle Époque paulista e carioca. Para isso, trabalhamos com os conceitos de narrador não digno de confiança (RICOEUR, 1997) e narradorcronista (BENJAMIN, 1994). Concluímos que Costallat (1999) constrói Rosalina para alertar os seus leitores e condenar as atitudes de uma mulher influenciada pela Belle Époque, enquanto Tácito (1998) vangloria-se de Mme. Pommery, que apenas segue as regras de uma sociedade hipócrita.
\end{abstract}

Palavras-chave: Belle époque. Madame Pommery. Mademoiselle Cinema. Cosmopolitismo.

Abstract: This paper aims to analyze Madame Pommery, by Hilário Tácito, and Mademoiselle Cinema, by Benjamim Costallat, focusing on the main characters and how they are portrayed, considering the context of Bellé Époque from São Paulo and Rio de Janeiro. For this, we work with the concepts of unreliable narrator (RICOEUR, 1997) and narrator-chronicler (BENJAMIN, 1994). We conclude that Costallat (1999) constructs Rosalina to alert the readers and condemn the attitudes of a woman influenced by the Belle Époque, while Tácito (1998) boasts Mme. Pommery, who only follows the rules of a hypocritical city.

Key-words: Belle époque. Madame Pommery. Mademoiselle Cinema. Cosmopolitianism.

Resumén: En este articulo se pretende a analizar Madame Pommery, de Hilário Tácito, y Mademoiselle Cinema, de Benjamim Costallat, con foco em los personajes principales y como ellas están retratadas, tenendo en cuenta que están insertadas en el contexto de la Belle Époque de São Paulo y Rio de Janeiro. Para eso, trabajamos com los conceptos de narrador no digno de confianza (RICOEUR, 1997) y narrador-cronista (BENJAMIN, 1994). Concluimos que Costallat (1999) construye Rosalina para alertar sus lectores y condenar las atitudes de una mujer afectada por la Belle Époque, mientras que Tácito (1998) vanagloriase de Pommery, que solamente sigue lãs reglas de una sociedad hipócrita.

Palabras clave: Belle époque. Madame Pommery. Mademoiselle Cinema. Cosmopolitismo 


\section{Introdução}

A Belle Époque é um marco na história por se constituir como um período cosmopolita no final do séc. XIX, na Europa, caracterizada por um novo modo de pensar, agir, vestir-se, pela expansão urbana, pelo processo de higienização e pelas transformações artísticas e científicas. Com os avanços tecnológicos, que também culminaram no desenvolvimento da comunicação, junto ao crescimento urbano, nesse período, os cidadãos franceses passaram a fazer atividades mais mundanas: para os homens, os cabarés e os bares eram as principais atrações; para as mulheres, os cafés, teatros e magazines. No Brasil, mais especificamente no Rio de Janeiro e em São Paulo, também tivemos uma Belle Époque inspirada na francesa, onde houve o desejo de modernidade e a importação do ideal francês para se alcançar esse objetivo. No entanto, esse momento histórico se configurou aqui de maneira diferente, pois apesar de trazer "o dinamismo da metrópole para a capital brasileira, [...] em troca acabou negando aspectos da brasilianidade" (MILAGRE JÚNIOR; FERNANDES, 2013, p. 30). Além disso, aqui, se aos homens era "permitido" frequentar os bordéis, por outro lado, os mais conservadores questionavam se as moças "de família" deveriam mesmo frequentar os cafés e teatros trazidos pela influência francesa, o que acabou por trazer a discussão em torno do papel da mulher em meados da década de 1920.

Segundo Milagre Júnior e Fernandes (2013), antes de aprofundar a discussão sobre a Belle Époque, é preciso distinguir os conceitos de modernização e modernismo para melhor compreender o que é a modernidade', já que a última é um processo de mediação entre os dois primeiros, sendo definida pelo autor como experiência histórica. Sendo assim:

modernização, portanto, refere-se a esse processo dinâmico, de passagem, que ocorre com a sociedade, gerando 'turbilhão', que seriam processos importantes nesse momento, como: descobertas científicas, industrialização, expansão urbana, os Estados Nacionais, movimentos de massa, um mercado mundial capitalista etc. (MILAGRE JÚNIOR; FERNANDES, 2013, p. 21).

\footnotetext{
${ }^{1}$ Ressaltamos, neste ponto, que, embora a modernidade seja um período cuja origem antecede o século XIX, neste artigo, estamos trabalhando especificamente com alguns aspectos que eclodiram no século XIX e seus desdobramentos para o período da Belle Époque.
} 
Já o modernismo se refere ao cultural e ao social, no qual o homem é agente e receptor desse processo de modernização. Dessa maneira, a modernidade é alcançada quando o modernismo e a modernização a compõe. O autor destaca essas concepções para realizar uma comparação entre a Belle Époque francesa e a brasileira, pois defende que, no Brasil, não se alcançou de fato a modernidade, e sim, a modernização.

Outro tema vinculado à Belle Époque brasileira que merece destaque é o de cosmopolitismo, que caracteriza a tendência à "imitação" do padrão europeu e se contrapõe ao localismo, que é nacionalista (CANDIDO, 2006). Ser cosmopolita é também ter uma "postura política e intelectual eminentemente marcada pelo universalismo" (DRUMOND, 2009, p. 2). Ou seja, nesse sentido, é defender que somos parte de uma cultura maior do que a do nosso país, uma cultura mundial, que também deve ser considerada.

Interessante notar que, embora, no Brasil, se buscasse esse padrão francês e o rompimento com o colonialismo, a tradição permaneceu e, com ela, marcas de um Brasil-colônia. Assim, no Rio de Janeiro, a modernização aconteceu por interesses da elite, de forma conservadora e superficial, especialmente pelo desejo de prestígio intensamente ligado a produtos de luxo importados, às vestimentas francesas, à incorporação de palavras do francês etc. - e a preocupação em esconder as camadas menos abastadas da sociedade sem resolver efetivamente os reais problemas, como a fome e o desemprego. Criam-se, então, largas avenidas e edifícios inspirados na arquitetura francesa, tendo como resultado a retirada dos antigos moradores que, sem lugar para ir, acabaram por se abrigar no que hoje chamamos de favelas.

Nas primeiras décadas do século $\mathrm{XX}$, também houve mudanças no comportamento feminino, pois as mulheres das classes mais abastadas iam para teatros, cafés, confeitarias, vestiam-se de acordo com a moda francesa e questionavam o papel que lhes cabia na sociedade. Em contrapartida, essas mudanças inquietavam os mais conservadores, que se sentiram no dever de reforçar a mulher como "do lar" e detentora da "honra" da família, o que caracterizou um período de ambiguidade, já que os costumes modernos eram considerados sedutores, mas também perigosos. Assim, “o menor sinal de flexibilização na divisão sexual das funções no interior da família era repercutido pelos conservadores e reformistas como uma ameaçadora vaga modernizante" (MALUF; MOTT, 1998, p. 385). Era função, então, da mulher ser 
prendada - saber cozinhar, costurar, bordar - e, caso ela trabalhasse, o que só ocorria com a autorização do marido e para determinados empregos, como secretária ou professora, não podia ser desleixada com as atividades domésticas. Mas Maluf e Mott (1998) destacam que mulheres pobres - assim como negros, imigrantes e operários eram as mais "fiscalizadas" pela elite carioca e paulista; assim, através de publicações em revistas e jornais e livros, "[...] as elites transformaram em ameaça os relacionamentos ajustados por padrões mais flexíveis e simétricos, classificando de imorais as uniões cujo epílogo não coincidia com o casamento" (MALUF; MOTT, 1998, p. 387).

Em São Paulo, também não foi diferente: “A modernidade, a qual tanto se aspirava, se materializava na tentativa de eliminação dos costumes tradicionais, [...] bem como havia um esforço político em se construir uma imagem de cidade moderna" (NASCIMENTO, 2012, p. 2). Nesse período, por essa necessidade de rompimento com a tradição colonial, intensifica-se a vida noturna, constroem-se cafés e teatros e surgem as prostitutas de luxo, consideradas responsáveis por trazer o refinamento europeu e o como agir de uma mulher moderna. Rago (1993) destaca que "se de um lado as prostitutas foram estigmatizadas enquanto um contra ideal para as jovens de família, por outro também foram aceitas socialmente enquanto transmissoras de hábitos mais civilizados [...]" (RAGO, 1993, p. 43). Assim, aos homens era permitido ingressar nesse universo de bordéis, bebidas e sedução. Quanto às mulheres, o "ser moderna" limitava-se a determinados lugares que eram permitidos para as "jovens de família”, enquanto outros eram apenas frequentados pelas meretrizes. A "moral e os bons costumes" também não permitiam que assuntos como virgindade, por exemplo, fossem debatidos e deixassem de ser tabus, o que era reforçado pelo ideal de mulher "de família”, "honesta”, "boa moça”.

Entre as jovens da elite, as missas deixavam de ser o entretenimento principal e a frequência aos passeios públicos, confeitarias, teatros, cinemas e clubes, assim como as novas práticas esportivas e a própria inserção no mercado de trabalho, seja enquanto estudantes, seja enquanto normalistas, professoras ou meras consumidoras, davam-lhes maior visibilidade. [...] Na Confeitaria Castelões, as famílias respeitáveis retiravam-se no final da tarde, antes que as "cocotes" invadissem espalhafatosamente o espaço [...] (RAGO, 1993, p.35/36).

Dessa maneira, a Belle Époque carioca e paulista se caracterizaram por um período complexo, em que houve grandes inovações tecnológicas e, ao mesmo tempo, 
uma intensificação dos problemas sociais, além do papel da mulher ser fonte de preocupação para a elite conservadora, já que as mulheres também almejavam o progresso e tudo que ele estava permitindo, como os cafés e teatros, a moda francesa.

Em meio a esse contexto, temos as obras pré-modernas Madame Pommery, de Hilário Tácito, narrativa que ocorre em São Paulo, no bordel de Pommery; e Mademoiselle Cinema, de Benjamim Costallat, ambientada no navio que parte do Rio de Janeiro para a França, o Arlanza, e em Paris. Ambas são protagonizadas por personagens femininas, no entanto, Pommery é uma prostituta polaca, que se passa por francesa, e o mais importante: é uma empreendedora, que veio, segundo o narrador, para "civilizar" São Paulo. Pommery é justamente uma personagem que carrega o que Rago (1993) afirma: é um contra ideal, mas também um símbolo do que é ser moderna. Por outro lado, Rosalina pertencente à elite carioca e, consequentemente, com acesso a bens e valores da Belle Époque francesa. Por esse motivo, imita comportamentos, como frequentar os salões, teatros, cafés e magazines, ter flirts e se vestir como a moda dita. Assim, acaba por representar uma "ameaça" aos mais conservadores. Na obra de Tácito (1998), temos a história de uma polonesa, Ida Pomerikowsky, que, posteriormente, escolhe chamar-se Mme. Pommery: "É provável que se trate de uma alcunha, proveniente da predileção pelo champanha Pommery” (TÁCITO, 1998, p. 33), como afirma o narrador. Vem para a América do Sul por sua ambição de desbravar o Novo Mundo em busca de riquezas. São Paulo é a cidade escolhida, pois, ainda no navio, encontra com sua antiga mentora e amiga, Zoraida, que a reconhece, mas como agora é uma verdadeira socialite, casada e com uma reputação a zelar, "viu e reconheceu Mme. Pommery. Mas, quando deu fé que a antiga discípula a encarava boquiaberta, de relance vislumbrou os perigos iminentes em um encontro daquela espécie; [...] Voltou-lhe a face. E comeu uma batata" (TÁCITO, 1998, p. 33). Assim, escolhe São Paulo como palco não de vingança, mas para mostrar a Zoraida - e para a elite paulista - todo seu potencial, e lá inaugura o bordel AuParadisRetrouvé (No paraíso reencontrado). Já na obra de Costallat, temos a história de Rosalina, que se muda, junto com sua família, para a França. Lá, vive todo o glamour da Belle Époque, frequentando bailes, bebendo champanhe, fazendo compras e frequentando as garçonnières, locais destinados a encontros amorosos, envolvendo-se com diversos homens.

Para realizar a análise dessas obras, classificamos Hilário Tácito, na verdade um pseudônimo para o autor José Maria de Toledo, como um narrador não digno de confiança. Sobre esse tipo de narrador, Ricoeur (1997) afirma: 
Ao contrário do narrador digno de confiança, que garante a seu leitor que não realiza a viagem da leitura com vãs esperanças e falsos temores acerca não só dos fatos relatados como também das avaliações explícitas ou implícitas dos personagens, o narrador indigno de confiança desordena essas expectativas, deixando o leitor na incerteza sobre até a que ponto ele quer, afinal, chegar.(RICOEUR, 1997, p. 281)

Enquadramos Tácito nesse tipo de narrador porque, durante toda a sua obra, utiliza a ironia, por exemplo, quando afirma ser historiador, e não romancista, alegando que a história de Mme. Pommery é verídica e de extrema importância para a Belle époque paulista. Além disso, o leitor fica confuso, inicialmente, sobre até a que ponto ele quer, afinal, chegar. Por outro lado, o narrador criado por Costallat, narrador-cronista, é para Benjamim (1994) um narrador que pode representar episódios ou personagens como modelos do mundo, assim, recria a realidade de acordo com uma perspectiva própria. Dessa maneira, percebemos que, embora Mademoiselle Cinema seja um romance, há traços de crônica, que marcam um posicionamento do autor em relação a sua própria personagem, Rosalina, concretizados, em alguns momentos, através da ironia; ademais, o autor faz seu próprio retrato da Belle Époque e da elite carioca. Classificar os narradores nos permitiu perceber como eles constroem suas personagens principais, o que também nos possibilita observar que juízos de valor Tácito e Costallat fazem ao comportamento de Mme. Pommery e de Melle. Cinema, respectivamente, nesse contexto da Belle Époque nas cidades de São Paulo e Rio de Janeiro.

Além disso, o uso da ironia é recorrente nas duas obras e, segundo Muecke (1995), o leitor, ao reconhecer a ironia, percebe a pretensão do autor por ela. Assim:

O ironista, em seu papel de ingênuo, propõe um texto, mas de tal maneira ou em tal contexto que estimulará o leitor a rejeitar o seu significado literal expresso, em favor de um significado "transliteral" não-expresso de significação contrastante. (MUECKE, 1995, p. 58)

Por isso, observamos como esse recurso foi utilizado nas obras, o que auxiliou na análise, já que, especialmente no caso de Madame Pommery, compreender a ironia presente na obra é crucial para compreender a crítica realizada pelo Hilário Tácito, pois o narrador satiriza a elite, que se julga moderna, quando não é, através da criação de uma 
personagem constantemente comparada a grandes cortesãs europeias, personagens históricas, responsável pelo desenvolvimento de São Paulo, quando, na verdade, busca apenas o benefício próprio e ser aceita pela alta sociedade. Em Mademoiselle Cinema, esse recurso também é utilizado, porém de outra maneira: o narrador, ao retratar Rosalina, recorre ao uso de diminutivos para marcar que, embora ela acredite ser uma mulher, ainda é apenas uma criança, o que a torna mais facilmente influenciável pela Belle Époque. Esse uso reforça um posicionamento que o narrador tem a respeito de sua personagem, tratando-a como imatura e condenando as suas atitudes. Rosalina acaba por servir de exemplo, para o narrador, do que as mulheres não devem fazer.

À medida que apresentamos o enredo das obras, buscamos analisar, a partir de uma abordagem comparatista, as personagens femininas: como elas são retratadas dentro do contexto da Belle Époque? E, além disso, como o ser moderno é apresentado nas obras e quais as posições dos autores frente às mudanças promovidas durante a Belle Époque.

\section{A Madame Pommery de Hilário Tácito}

Hilário Tácito é um pseudônimo escolhido pelo autor José Maria Toledo, o que já nos antecipa uma obra irônica. Segundo Moraes (1998),

se 'Hilário' carrega uma série de significados relativos ao riso, 'Tácito' remete a uma referência séria, evocando a figura do famoso historiador latino da antiguidade, PubliusCornélius Tácito. Dessa forma o cognome fictício do escritor concentra um par de opostos que, conjugando humor e seriedade, atenta uma vez mais para os acordos 'tácitos' entre ficção e realidade. (MORAES, 1998, p. 5),

Assim, há uma ambiguidade nesse narrador, assim como no pseudônimo, responsável por criar um efeito irônico na obra, pois o narrador se diz historiador, sério e confiável, defendendo que a sua personagem é verdadeira, mas o leitor sabe que isso não 
ocorre. Tácito constrói um narrador-testemunha, que conta a história de Madame Pommery em primeira pessoa, por ser um personagem secundário, apenas participante da Belle Époque paulista, contexto em que se passa a obra. Ao contar a história de Ida Pomerikowsky, de maneira não linear, o tempo todo se utiliza de digressões e faz interferências na história de sua personagem para fazer comentários, associações de Pommery com outras cortesãs, referências históricas e literárias. Classificamos Tácito como um narrador não digno de confiança, pois brinca com o leitor sobre o que realmente quer dizer. Embora afirme que Pommery é uma mulher que realmente existiu e foi de extrema importância para a Belle Époque brasileira, o autor apresenta uma personagem interessada apenas no seu benefício próprio e que, na verdade, em nada contribui para a história brasileira; mas, por outro lado, o narrador também a defende a todo o momento de maneira irônica.

O capítulo I, denominado "Em que se trata do autor da história e dos motivos que teve para escrever", apresenta para o leitor os objetivos do narrador, Hilário Tácito:

Coisa nova há de parecer a muita gente que este livro, cujo propósito declarado é narrar a vida de uma personagem tão principal como Mme. Pommery, logo no começo se extravie do seu reto caminho, trocando assunto de tamanho momento por outro apagado e tão pouco interessante, como seja a personalidade incógnita do autor (TÁCITO, 1998, p. 11).

Podemos notar a ênfase na sua personagem, tão principal, ou seja, tão importante que sua história merece ser contada. No entanto, a abertura do livro aborda o próprio narrador, e não Pommery, embora ele se autodefina como apagado e pouco interessante, o que já demonstra a entonação irônica por utilizar-se da seriedade ao se apoiar na figura de um historiador e, no final das contas, fazer exatamente o contrário do que disse. Ainda nesse capítulo, afirma: "Mas eu pretendo levar a cabo esta obra com método rigoroso, e sem jamais me apartar uma linha do meu assunto principal, nem da verdade da qual pretendo fazer o meu maior título à veneração dos vindouros" (TÁCITO, 1998, p. 14). Nesse trecho, é importante ressaltar como o narrador declara que também não irá se afastar da verdade. Introduz, então, Mme. Pommery na história, comparando-a com a Marquesa de Santos, amante de Dom Pedro I, e Mme. Pompadour, amante do Rei Luís XV. Ambas foram grandes cortesãs, cultas, belas e influentes nas cortes brasileira e francesa, respectivamente. E, ao longo da história, o autor fará referências a outras 
cortesãs, declarando que Mme. Pommery é tão influente quanto elas, com o intuito de convencer o leitor da importância de sua personagem.

Assim, o narrador começa a história de Pommery explicando como ela desembarcou em São Paulo. No entanto, quebra mais uma vez o acordo com o leitor de não se desviar do assunto principal e relata um quadro-geral paulista antes da chegada de Pommery: o bonde elétrico ainda era novidade; poucos automóveis apareciam nas ruas; o Teatro Municipal ainda não havia sido construído; a cerveja ainda era a bebida preferida, e não o champanhe, sendo assim: "Para se operar uma inovação deste quilate foi necessária a concorrência de circunstâncias excepcionais, juntamente com o gênio reformador e construtor de Mme. Pommery" (TÁCITO, 1998, p. 19); e a moda era constituída por chapéus de palha e paletós de aba, ainda sem influência do requinte francês. "Andavam as coisas assim, nesta lástima, quando aportou Mme. Pommery por estas bandas" (TÁCITO, 1998, p. 19). Assim, podemos perceber também um tom de deboche do narrador, ao comparar Pommery com grandes cortesãs europeias, que realmente tiveram influências políticas, enquanto a sua personagem é responsável, segundo ele, por substituir a cerveja pelo champanhe, influenciar em alguns detalhes na moda e criar uma casa de espetáculos.

Da mesma maneira que eleva sua personagem principal, também deseja mostrarse como um pensador erudito e grandioso. Por isso, alude, em diversos momentos, a momentos históricos e cita passagens literárias, muitas vezes na língua original, com o intuito de se mostrar culto e, dessa forma, tentar ganhar a confiança do leitor. Mas essas passagens também são utilizadas para engrandecer a personagem, como podemos ver nesse trecho em que compara Mme. Pommery a Pedro Álvares Cabral:

[...] Se Cabral arribou na Enseada de Santa Cruz e Mme. Pommery desembarcou em Santos, foi porque Cabral era um homem bólido, como Mme. Pommery é uma mulher-meteoro, [...]. Cabral por ser necessário aos destinos do Brasil, Mme. Pommery porque não era menos necessária aos destinos de São Paulo (TÁCITO, 1998, p. 40).

Através da ironia, compara Mme. Pommery a diversos personagens famosos da história e literatura mundial. Antes de chegar a São Paulo, Pommery encontra, no navio, Zoraida, sua antiga mentora, quando ainda se encontrava na Polônia; mas Zoraida, agora casada com um figurão importante, o Coronel Fidêncio Pacheco Izidoro, desdenha de 
Pommery, finge que não a conhece. Mme. Pommery tenta subornar Zoraida, mas seu plano é em vão, pois agora, mulher casada, Zoraida consegue limpar todo o seu passado obscuro. Assim, “Aos olhos argutos de Mme. Pommery o descobrimento de Zoraida não valia nada em si, além do susto. A sua grande descoberta daquele dia foi o Coronel Pacheco Izidoro" (TÁCITO, 1998, p. 43). É nesse momento, então, que Mme. Pommery percebe que mesmo uma mulher como Zoraida pode subir na vida e inicia seu plano para alcançar o sucesso também.

Eis que conhece Pinto Gouveia, comerciário de café, Dr. Filipe Mangancha, tesoureiro da Companhia Paulista de Teatros e Passatempos, e Romeu de Camarinhas, almoxarife da Intendência.

Difícil coisa seria descobrir para qual dos três pendesse o coração de Mme. Pommery. É possível que balançasse de um para outro, isocronicamente. O que, porém, está fora de dúvida é que soube aproveitar-se de cada um por sua vez com maravilhosa indústria [...] (TÁCITO, 1999, p. 54).

Pommeryconvence Pinto Gouveia a dar-lhe dinheiro para abrir o AuParadisRetrouvé; tornam-se sócios. No entanto, logo Mme. Pommery coloca em ação seus planos e consegue se tornar a única dona do bordel. Do Dr. Mangancha, consegue a influência teatral para criação dos espetáculos e do cassino, responsáveis por movimentar a casa. Por fim, desfaz-se também dele e se envolve com Camarinhas, começando a fase mais estável e glamourosa do AuParadis.

"Que uma simples rameira arrufinada haja influído nos bons ou maus costumes de uma capital como São Paulo, é verdade que pode passar por ousadia aos olhos de pessoas inexpertas, ou mal informadas sobre os bastidores da civilização" (TÁCITO, 1998, p. 112). Ainda nesse mesmo capítulo, Hilário Tácito nos dá um exemplo de como Pommery atuou na cidade de São Paulo: se antes as cortesãs não podiam aparecer em público, nem frequentar os mesmos lugares que as moças de família, agora isso havia mudado. Ela também muda os espetáculos da cidade e influencia na moda. A personagem Madame Pommery pode ser considerada uma representação da própria Belle Époque brasileira: superficial, mas que facilmente ludibria a elite da "Botocúndia", especialmente por fazê-la crer que modernizou a cidade de São Paulo. E o narrador também se dirige aos moralistas da "Botocúndia", que passam a condenar a 
modernização causada por Pommery por ser escancarada, também os considerando hipócritas, já que "se alguns foliões de todo o ano esperam o carnaval para fingir de moralistas, o desastre não chega a ser enorme, porque os moralistas no mesmo ponto lhes dão o troco disfarçando-se em foliões" (TÁCITO, 1998, p. 121). O narrador, nesse capítulo, defende Mme. Pommery e aborda a própria cidade de São Paulo:

A cidade de S. Paulo é uma capital cosmopolita, onde ao antigo elemento nacional, ainda em maioria, se vieram misturar, numa indigesta confusão de raças e civilizações, outras gentes escumadas de todas as terras do mundo, desde a Grécia até o Japão.

Daí a grande e natural instabilidade com que aqui se apresentam todos os usos e costumes, sempre inclinados a revestir formas, ora extravagantes, ora ridículas, no seu desenvolvimento excessivamente rápido, de contínuo perturbado por influências forasteiras.

(TÁCITO, 1998, p. 112).

Reconhece, assim, Mme. Pommery, de maneira irônica, como importante para o progresso paulista, pois satiriza a "Botocúndia" paulista, de desenvolvimento excessivamente rápido, mas ainda assim de mente atrasada. $\mathrm{O}$ mais interessante é que a própria personagem, por fim, rende-se aos costumes sociais e morais e casa-se, pois era a "A única coisa que faltava, para o coroamento de sua vida, era o ingresso franco do grêmio social aristocrático" (TÁCITO, 1998, p. 147). Casar, embora já fosse muito rica, era o passaporte para entrar nessa elite que desdenhava do seu bordel, ao mesmo tempo em que o frequentava assiduamente; contraditório é o narrador dessa história, mas contraditória é também a elite da "Botocúndia". Mme. Pommery é uma personagem retratada pelo autor como malandra, porque aprende a jogar conforme as regras dessa cidade; a partir dela, o autor faz uma crítica à hipocrisia dessa elite que se julga moderna e cosmopolita, mas que é extremamente moralista e atrasada. Por isso é que Tácito a defende constantemente, pois se vangloria de sua personagem: ela faz exatamente o que uma meretriz poderia fazer para ser aceita socialmente. Por fim, não sabemos exatamente se ela vai casar ou não, mas imaginamos que sim. Devido a sua trajetória, Mme. Pommery não nos decepcionaria. 


\section{A Mademoiselle Cinemade Costallat}

Costallat (1999) narra de maneira linear a história de Rosalina, uma adolescente que as más línguas chamam de Melle. Cinema, por ser um mero espetáculo e falsa como o cinema. Ela está indo morar em Paris com seus pais, como dissemos anteriormente. No início do romance, que se passa ainda no navio, o Arlanza, logo nas primeiras páginas, o narrador já nos apresenta sua personagem:

\footnotetext{
"Rosalina, calças de pijama, o busto nu, os minúsculos seios de dezessete anos, atrevidos e brancos, terminado por duas manchinhas cor de rosa quase imperceptíveis, olhou para a própria imagem, para a sua imagem de garota adorável, e sorriu" (COSTALLAT, 1999, p. 35).
}

É interessante como esse primeiro trecho já configura e antecipa, para o leitor, essa personagem. Sendo uma adolescente ainda, o narrador enfatiza os seios de Rosalina, ainda em formação, e utiliza o diminutivo para dar um ar de infantilidade para ela, deixando claro que, embora já tenha 17 anos e seja quase uma mulher, ainda possui manchinhas no corpo, é ainda uma menina. Aliás, o diminutivo é algo utilizado pelo autor em toda a obra ao mencionar a sua personagem, acompanhado de um tom irônico que a inferioriza. Rosalina, então, está mais próxima de uma criança imatura do que de uma mulher responsável. Além disso, o narrador nos mostra que ela é uma garota adorável e sabe disso. Nesse olhar-se ao espelho, vemos a profunda admiração que ela tem por si mesma e um quê de egocentrismo. Assim, nesse parágrafo, já percebemos um desgostar do narrador em relação a sua própria personagem, por apresentá-la como infantil e egocêntrica.

Estando os personagens ainda no navio, o narrador nos explica o motivo da viagem: o pai de Rosalina, Dr. Martins Pontes, sai do Ministério e decide morar em Paris. "No dia 16 de novembro, ele era visto pelas ruas, com um fraque usado, uns sapatos gastos, um chapéu de Chile sujo e disforme. Fazia pena... Os transeuntes abriam alas, respeitosamente, para toda aquela honestidade" (COSTALLAT, 1999, p. 37). O narrador deixa transparecer a ironia ao apresentar o Dr. Martins Pontes, pois debocha das pessoas que acreditam que o pai de Rosalina é honesto porque sai paupérrimo do Ministério. No 
trecho a seguir, denota uma crítica ao povo, que, para o narrador, é ingênuo e imbecil, como afirma um pouco mais à frente:

Não há mais santa ingenuidade ou mais santa imbecilidade do que a do povo. Basta um ministro, um desses ministros salafrários que temos tido, [...], andar regularmente, [...], de bonde, não fumar charutos, nem ostentar roupas novas, para estarmos convencidos de que a sua administração foi honesta e sensata (COSTALLAT, 1999, p. 37).

Assim, o narrador define a sua personagem principal como infantil e seu pai como um salafrário e desonesto. Ainda a bordo do Arlanza, Rosalina começa a viver o glamour da Belle Époque:

[...] afundada num maple, as meias de seda à mostra até as ligas, tirou de sua carteirinha de ouro um cigarro loiro e bem perfumado, e começou a deixar seus lábios sangrentos de carmim, as primeiras fumaças azuis de seu Chevalier d'Orsay - já estava longe, longe, muito longe do Rio [...] (COSTALLAT, 1999, p. 42).

Nessa descrição, vemos que Rosalina é uma típica socialite, totalmente influenciada pelo modo de agir e ser que a Belle Époque acabou por ditar. Nota-se também novamente o uso do diminutivo quando o narrador fala em carteirinha, o que contrasta com o resto de seus pertences: meias de seda e cigarro indicam que se trata de uma mulher, mas a carteira no diminutivo ainda traz um ar de infantilidade para a personagem. Além disso, podemos observar que, assim como a fumaça do cigarro que se esvai, dissipam-se também as recordações e a saudade do Rio: "Aos dezessete anos, como aliás em qualquer idade, uma mulher é capaz de todas as traições. Aos dezessete anos, a mulher, além de trair os outros, é capaz de trair a si mesma. Assim Rosalina traíra suas próprias saudades..." (COSTALLAT, 1999, p. 42). A partir desse trecho, vemos também que o narrador apresenta não só a perspectiva que tem sobre Rosalina, mas de todas as mulheres, como sendo a traição algo da natureza da mulher adulta. A personagem, assim, cumpre o seu papel e rapidamente deixa-se influenciar pela Belle Époque francesa, seu objetivo agora é apenas se divertir e ter flirts: 
Aliás não há grande diferença entre meretrizes e certas meninas da época. O flirt para a prostituta chama-se michete o bordel para a menina de família chama-se dancing. Com uma ligeira diferença na nomenclatura, as instituições são perfeitamente idênticas entre si [...] (COSTALLAT, 1999, p.43).

Em vários momentos, o narrador censura as mudanças que surgem em meados da década de 20, como podemos perceber em um dos trechos que conta um dos beijos de Rosalina, provavelmente o primeiro:

Rosalina, naquele beijo, deu-se toda. Ainda era ingênua. E pensava que, como nos contos de fadas, depois daquele beijo, casar-se-ia com o príncipe encantando, viveria longos anos e teria muitos filhoss... Mas o amor, hoje, é um sportcomo outro qualquer. Beija-se como se joga tennis, e namora-se como se faz o footing. [...] Rosalina não sabia ainda... Deu-se toda, de todo o coração. Mas aquele beijo, para o elegante encasacado, fazia parte da dança. [...]Mas um dia Rosalina compreendeu. [...] Deixou o lirismo de seus dezesseis anos. Deixou de ser inocente. Ficou, depois de uma curta desilusão, menina de sua época (COSTALLAT, 1999, p. 52-53).

Logo percebemos que, para o autor, Rosalina é fruto de uma época. Há, então, uma crítica mais à Belle Époque do que à própria personagem, já que a busca pelo moderno e pelo ser cosmopolita é que, para Costallat, acaba criando as Rosalinas. Utilizase, então, da personagem para trazer o questionamento em torno da "moral e dos bons costumes". É interessante notar como o narrador contrasta a Rosalina aos dezesseis anos, ainda ingênua, e a Rosalina, aos dezessete, que ainda não cresceu suficientemente para poder discernir o certo e o errado, deixando-se levar pelos bailes, roupas, cafés, enfim, pelas tendências francesas, tornando-se menina de sua época.

É também no Arlanzaque conhece e inicia um romance com Roberto Fleta, escritor brasileiro, autor do romance A menina que pecou, livro com que Rosalina muito se identifica. Na história do escritor Fleta, há também uma jovem garota que se deixa levar pelas paixões, que acaba pecando e "a sociedade a condena e a repele [...]" (COSTALLAT, 1999, p. 58). Há, então, uma conexão desse romance fictício com a própria história de Rosalina, pois ambas as personagens são facilmente influenciadas pelo meio; além disso, o narrador já nos antecipa um possível final trágico para Rosalina. Ao conhecer Roberto, o narrador deixa claro para o leitor que o escritor avisa Rosalina que é 
casado, mas ela "faz-lhe uma caretinha enciumada. Quanto ao idílio dos dois, continuou mais intenso ainda, como que aumentado por essa revelação!" (COSTALLAT, 1999, p.64). A responsabilidade de dizer não a um homem casado acaba caindo mais para Rosalina, já que ela acaba encantando-o e tentando-o de tal maneira que faz com que ele se porte como um adolescente, vivendo um primeiro amor. É também Rosalina a mente por trás do plano que os coloca a sós, e a Fleta só cabia aceitar, pois, segundo o narrador: "Os Romeus de hoje é que ficam à janela; as Julietas é que arranjam escada de corda e tudo mais para subir até eles...”. Novamente, Rosalina é responsabilizada, pelo narrador, por suas ações, mas, ao mesmo tempo, é também um fruto do meio, pois há uma comparação com tempos passados quando o narrador marca que hoje é que os Romeus ficam à janela. O plano se concretiza e, com Fleta, Rosalina perde a virgindade.

Logo após esse episódio, a família Pontes chega à tão sonhada Paris. Costallat (1999) faz um retrato da cidade, descrevendo as vitrines, as magazines, as mulheres fazendo compras, as ruas cheias, os cavalos na rua; porém, o desdém prevalece: “Aquilo era Paris? Aquelas paredes imensas, naquela rua sem fim, sujas de carvão, sob aquele céu, frio e triste, cor de café com leite pálido? Aquilo é que era Paris" (COSTALLAT, 1999, p. 71). A ironia também se faz presente ao apresentá-la:

\footnotetext{
Mas o taxi passa por um grande magazin. Uma casa de seis andares, atulhada, como uma arca de Noé. Diante das suas portas, centenas de criaturas se atropelam. Mulheres, só mulheres, gesticulam como num meeting monstro. Gesticulam e gritam aos empurrões. Alguns policiais procuram reestabelecer a ordem. Que será? É um saldo de algumas rendas e de algumas fitas que o grande magazinestá liquidando! Só isso. Nada mais. Eis Paris! (COSTALLAT, 1999, p. 71-72).
}

O que parecia ser algo sério nada mais é que uma liquidação. Além disso, Paris é retratada por ele como palco de diversas lojas, cafés e teatros, mas também como uma cidade superestimada. No final das contas, para o autor, Paris não é tudo o que dizem ser, mas o suficiente para encantar Rosalina, especialmente pelo que ele considera supérfluo, como as roupas nas vitrines, os salões, os automóveis: “[...] a cidade maravilhosa das mil orgias, a cidade-beijos, a cidade-gozo, a cidade-delírio, a mais sensual e a mais feminina cidade do mundo!" (COSTALLAT, 1999, p. 75).

Assim, essa Paris fascinante, aos olhos de Rosalina, e perigosa, aos olhos do narrador, acabou por ser a maior companheira da personagem, já que o pai dela ia para a 
farra, enquanto a mãe ia fazer compras (inicialmente, Rosalina a acompanhava, mas depois se separaram e cada uma fazia compras e ia a lugares de suas preferências.). Então, "Melle. Cinema, em plena liberdade, todos os dias atirava-se ao asfaltado da cidade" (COSTALLAT, 1999, p. 101). A Belle Époque francesa acabou por corromper não só Rosalina, que cede às paixões da década de 20, mas também os pais, que se tornam ausentes para viver a cidade. Sozinha, "Paris a alucinava. No seu cérebro de criança histérica passavam as mais loucas idéias e os mais loucos desejos" (COSTALLAT, 1999, p. 101). E é dessa maneira que retoma seu romance com Roberto Fleta. Porém, algumas páginas depois, passa a refletir sobre o caso com Fleta e eis que chega a essa conclusão:

Cansei-me de Fleta. Por quê? Porque ele era um homem só e preciso de muitos amantes, como, no tempo em que eu dançava, precisava de muitos dançarinos. [...]

- Não tenho culpa se me sinto assim. Desde criança, foram, pouco a pouco, por uma sábia educação, excitando todos os meus sentidos. No foot-ball, rapazes poucos vestidos; no banho de mar, homens quase nus; nos cinemas, beijos terríveis; nos bailes, carne contra carne; - isso é que eu fui vendo e presenciando desde a idade em que, geralmente, as outras meninas brincam com bonecas...

Fizeram de mim o que sou hoje. Não tenho amor por ninguém. Tenho amor, isso sim, paixão febril, pelos meus próprios sentidos! (COSTALLAT, 1999, p. 117).

Nesse trecho, o autor nos mostra a frieza de Rosalina ao acabar seu romance com Fleta. O motivo? É como foi criada nesse mundo imoral, logo, não poderia agir de maneira diferente. Embora seja retratada, pelo autor, como fria, egocêntrica, infantil e falsa, responsável por dominar completamente Fleta, que acaba viciado em cocaína, substituindo o vício na moça pelas drogas, Melle. Cinema não chega a ser uma vilã. Assim como seus pais, constantemente mostrados como ausentes - Sr. Martins pensa apenas em frequentar os bordéis, e a Sra. Martins deseja apenas fazer compras -, Rosalina representa o futuro de uma elite que se deixa influenciar pelo ser cosmopolita, pelo moderno. Costallat (1999), então, faz uma crítica a essa elite que se deixa facilmente levar pela influência francesa. É por esse motivo que o final da Melle. Cinema não poderia ser diferente: seu pai morre em um dos bordéis e Rosalina atende ao telefone e recebe essa trágica notícia; ela, então, vai ao bordel e presencia a triste cena. Com a mesma frieza com que ela deixa Fleta, as meretrizes do bordel também apenas querem 
esconder traços de que houve uma morte no bordel; não seria bom para os negócios. É isso que o autor defende como consequência de uma busca impensada pelo glamour, pela ganância de apenas querer viver, se divertir e nada mais.

Por fim, Rosalina volta ao Brasil e se relaciona com um homem, Mário, que a ama verdadeiramente. Ela o ama também, porém o narrador nos deixa claro que ela não se julga merecedora desse amor, pois será sempre a Melle. Cinema.

\section{Madame versus Mademoiselle}

Ambos os autores elaboram suas personagens com o intuito de fazer uma crítica à elite, especialmente por não julgarem a Belle Époque paulista e carioca como um momento em que a modernidade foi de fato alcançada. Além disso, os dois autores mostram as influências da Belle Époque, que repercutiu na moda, na cultura e no social também, porém se o narrador criado por Costallat possui um tom moralista, que condena a influência francesa, por outro lado, José Toleto cria Hilário Tácito com o intuito de debochar da elite da "Botocúndia", que pensa estar à frente do seu tempo por ter se modernizado, quando, no final das contas, possui uma mente atrasada e conservadora.

Assim, Costallat e Tácito constroem suas personagens principais de modo a realizarem essa crítica. Por esse motivo, Rosalina é facilmente influenciável pelo meio em que vive, aproveitando tudo que Paris tem a oferecer, sem pensar nas consequências de suas ações; por outro lado, Mme. Pommery é uma mulher que logo percebe as regras do jogo da socialite paulista, hipócrita, que julga de acordo com a moral alguns, mas não a todos, e não mede esforços para fazer parte dessa elite.

É interessante observar que Rosalina é justamente o tipo de mulher que Maluf e Mott (1998) afirmam que era considerada como uma ameaça pelos mais conservadores por frequentar cafés, bailes e teatros, questionando, dessa maneira, o papel da mulher na sociedade e não mais compactuando com a visão da moça "de família" e "do lar". A mãe de Rosalina também é uma mulher desse "tipo", e tanto ela como a filha são retratadas 
pelo narrador de maneira negativa. No entanto, o narrador "culpa" a influência da Belle Époque francesa, especialmente em relação à Rosalina. Todavia, ele também aborda uma natureza feminina que é traiçoeira, como se a mulher fosse mais facilmente persuadida pela superficialidade oferecida por Paris, e isso é reforçado à medida que utiliza a ironia para desmerecer sua personagem, representando-a como imatura e, assim, mais influenciável. Já como Madame Pommery é apresentada por Tácito se assemelha ao que é dito por Rago (1993) sobre as prostitutas: são as responsáveis por trazer as influências e hábitos europeus, que são seguidos pelas socialites, mas não servem como modelo de "boa" mulher: a "do lar".

Mas o que elas têm em comum é que ambas são construídas de modo a compreenderem que sexo é poder. Entretanto, Costallat mostra como isso pode ser perigoso; já Hilário, como o sexo levou Mme. Pommery, em uma sociedade hipócrita, ao sucesso do AuParadis e, por último, ao casamento, que não sabemos se de fato ocorreu, mas que indica, na história, a aceitação social de uma ex-prostituta. Por fim, Mademoiselle Cinema tem sua devida punição por viver desse modo que o narrador repreende, enquanto Pommery alcança seus objetivos, pois jogou bem. O cenário da história também se justifica, pois que lugar melhor para Rosalina sofrer más influências do que a própria Paris? E onde mais a hipocrisia da elite seria escancarada senão no bordel? Além do espaço, o tempo das obras ocorre de maneira diferente, pois se a história de Rosalina é narrada de maneira linear, a de Mme. Pommery não é. No caso da obra de Tácito, a não linearidade, composta por muitas digressões, é responsável também por constituir a ironia; enquanto a de Costallat, por ter um narrador-cronista, torna-se compreensível uma narrativa linear, já que o tempo cronológico determinado costuma ser uma das características da crônica. Dessa maneira, embora Mademoiselle Cinema seja um romance, há também traços de crônica na obra, apresentando também retratos de uma sociedade.

Outro aspecto relevante é que tanto Hilário Tácito como Costallat se utilizam da ironia, mas se compreender a entoação irônica de Tácito é decisivo para o entendimento da história, no caso de Costallat, essa entonação aparece mais sutilmente. Além disso, o narrador de Melle. Cinema ironiza sua própria personagem, pois deseja mostrar como ela ainda é infantil. Em muitos momentos utiliza diminutivos para enfatizar que ela ainda é uma criança, embora haja como adulta, o que nos mostra uma personagem facilmente influenciada pela Belle Époque francesa. No caso de Hilário Tácito, há um grau de complexidade que exige mais do leitor, pois em diversos momentos é preciso captar as 
referências que o autor faz não para perceber a ironia, mas para entendê-la. Além do que, o autor faz uso desse recurso constantemente. Se Costallat ironiza sua personagem, Hilário Tácito satiriza e debocha da elite da "Botocúndia".

Por fim, embora as narrativas estejam contextualizadas em lugares diferentes, na Belle Époque paulista e carioca, a partir da leitura das obras é possível perceber a massiva influência francesa que, de certa maneira, acabou por padronizar um modo de ser e viver dessas duas cidades, especialmente da elite, mas também como isso se deu de maneira superficial. Através da posição dos narradores, observamos que tanto Hilário Tácito como Costallat constroem suas personagens principais para fazer uma crítica à elite. No caso de Tácito, especificamente à elite da "Botocúndia", por se deixar influenciar apenas pelo que a Belle Époque francesa tem de mais superficial (champanhe, moda, espetáculos) e acreditar que isso é ser moderno. A Mme. Pommery acaba por ser uma representação da própria Belle Époque, e o narrador sai em defesa de sua personagem, pois sabe que ela apenas segue as regras ditadas por uma elite hipócrita, que direciona seu moralismo a quem lhes interessa. Já Costallat condena não apenas as atitudes de Rosalina, mas a própria Belle Époque francesa que a torna um fruto do meio, sem escapatória.

\section{Considerações finais}

A partir dos conceitos de modernismo, modernização e modernidade, contextualizamos as influências da Belle Époque francesa, apresentando de que maneira ela ocorreu nas cidades do Rio de Janeiro e São Paulo. E, de acordo com Milagre Júnior e Fernandes (2013), no Brasil, não houve a modernidade, apenas a modernização. Embora não tenhamos alcançado a modernidade, a modernização trouxe mudanças também no modo de agir das pessoas, que se espelhavam na moda e nos costumes franceses, buscando frequentar teatros, cafés e bordéis, com o intuito de se divertir. Isso acabou por trazer questionamentos em relação ao comportamento feminino, pois ia de encontro ao "ideal" apresentado pelos conservadores de como elas deveriam se portar no Rio de Janeiro (MALUFF; MOTT, 1998). Além disso, havia uma visão ambígua que a sociedade 
tinha das prostitutas em São Paulo, pois ao mesmo tempo em que as mulheres copiavam o que elas vestiam e o como elas se portavam, por muitas delas serem estrangeiras, não se aceitava que elas frequentassem os mesmos lugares que as moças "de família", por exemplo (RAGO, 1993).

Após descrevermos as circunstâncias em que as obras são narradas, explicamos, de maneira geral, o enredo de Madame Pommery e de Mademoiselle Cinema e classificamos Hilário Tácito como narrador não digno de confiança e Costallat como narrador-cronista, pois isso nos auxiliou a perceber a intenção dos autores, já que Hilário Tácito quebra a confiança e expectativas do leitor, criando um efeito irônico, para realizar uma crítica à elite, debochando dela também, enquanto Costallat, embora seja autor de um romance, transparece traços de crônica em sua obra, denotando também um posicionamento em relação a sua própria personagem, condenando-a por ser infantil e facilmente influenciável pela Belle Époque francesa.

Para realizar a análise, primeiramente contamos o enredo de Madame Pommery e, a partir do desenrolar da história, selecionamos trechos relevantes, com foco na personagem principal e no narrador. Utilizamos o mesmo critério para Mademoiselle Cinema. Como a ironia se faz presentes nos dois romances e sendo um recurso importante para o Tácito construir sua personagem principal e para o Costallat denotar um posicionamento a respeito de sua própria personagem, condenando-a, também escolhemos partes do texto em que fosse utilizado esse elemento. Após a análise de cada obra, traçamos um paralelo entre as duas.

Concluímos, então, que os dois autores realizam uma crítica à elite (embora de maneiras diferentes) e retratam a influência francesa, especialmente no modo de agir dos cariocas e paulistas. Além disso, embora Rosalina e Mme. Pommery sejam personagens retratadas de maneiras distintas, ambas logo percebem que sexo é poder. No entanto, se Hilário Tácito demonstra que Pommery usa isso a seu favor, pois é algo necessário para que ela alcance prestígio e, por fim, através do casamento, aceitação social, no caso de Costallat, ele condena essa atitude. Hilário Tácito sai em defesa de sua personagem, pois sabe que ela apenas segue as regras ditadas por uma elite hipócrita. Já Costallat condena não apenas as atitudes de Rosalina, mas a própria Belle Époque francesa, que é a maior responsável por influenciar garotas imaturas como a sua personagem principal. 


\section{Referências}

BENJAMIN, Walter. O narrador: considerações sobre a obra de Nikolai Leskov. Magia e técnica, arte e política: ensaios sobre literatura e história da cultura. São Paulo: Brasiliense, p. 197-221, 1994.

CANDIDO, Antonio. Literatura e Cultura de 1900 a 1945. IN: CÂNDIDO, A. Literatura e sociedade. Rio de Janeiro: Ouro sobre azul, 2006.

COSTALlAT, Benjamim. Mademoiselle Cinema. Rio de Janeiro: Casa da palavra, 1999.

DRUMOND, Adriano Lima. O cosmopolitismo literário de Joaquim Nabuco. Revista dEsEnrEdoS, Piauí, $\quad$ v.1, $\quad$ n.3, 2009. Disponível em: <http://desenredos.dominiotemporario.com/doc/o3_artigo_-adriano_drummond.pdf>. Acesso em: 10 jan. 2017.

MALUF, Marina; MOTT, Maria Lucia. Recônditos do mundo feminino. IN: SEVCENKO, N. História da vida privada no Brasil: república: da Belle Époque a Era do Rádio. São Paulo: Companhia das Letras, 1998.

MILAGRE JÚNIOR, Sérgio Luiz; FERNANDES, Tabatha de Farias. De F. A belle époque brasileira: as transformações urbanas no Rio de Janeiro e a sua tentativa de modernização no século XIX. Revista História em Curso, Minas Gerais, v. 3, n. 3, 2013. Disponível em: $<$ http://periodicos.pucminas.br/index.php/historiaemcurso/article/view/5337>. Acesso em: 22 dez. 2016.

MORAES, Eliane Robert. Entre a ironia e o deboche. IN: TÁCITO, H. Madame Pommery. São Paulo: Ática, 1998.

MUECKE, D. C. Ironia e o irônico. São Paulo: Editora perspectiva, 1995.

NASCIMENTO, Luciana Marino. Os salões da Belle Époque: uma leitura de Madame Pommery, de Hilário Tácito. Revista Recorte, Minas Gerais, v.9, n.1, 2012. Disponível em: <http://revistas.unincor.br/index.php/recorte/article/view/338>. Acesso em: 30 ago. 2016. 
RAGO, Luzia Margareth. Imagens da prostituição na Belle Epoque paulistana. Cadernos

Pagu, Campinas, n.1, p. 31-44, 1993. Disponível em: $<$ http://periodicos.sbu.unicamp.br/ojs/index.php/cadpagu/article/view/1679>. Acesso em 26 ago. 2016.

RICOEUR, Paul. Mundo do texto e mundo do leitor. IN: RICOEUR, P. Tempo e Narrativa: tomo III. Campinas: Papirus, 1997. pp. 273-314.

TÁCITO, Hilário. Madame Pommery. São Paulo: Ática, 1998.

\footnotetext{
* Agradeço à Profa. Dra. Inara Gomes Ribeiro (UFPE) pela valiosa contribuição para que esse trabalho pudesse ser realizado.

${ }^{* *}$ Mestranda em Letras pela Universidade Federal de Pernambuco.
} 